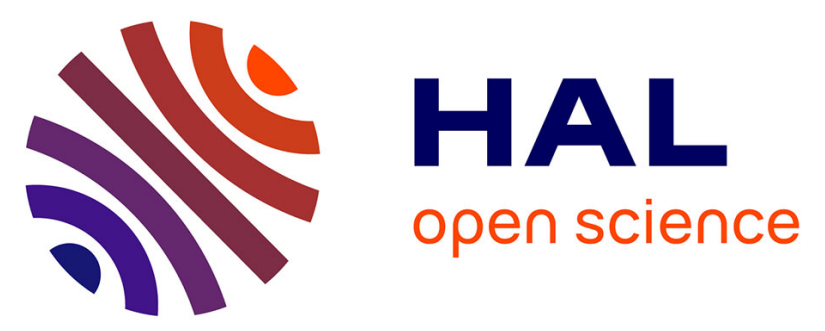

\title{
Effects of OPA1 mutations on mitochondrial morphology and apoptosis: relevance to ADOA pathogenesis.
}

\author{
Aurélien Olichon, Thomas Landes, Laetitia Arnauné-Pelloquin, Laurent J. \\ Emorine, Valérie Mils, Agnès Guichet, Cécile Delettre, Christian P. Hamel, \\ Patrizia Amati-Bonneau, Dominique Bonneau, et al.
}

\section{To cite this version:}

Aurélien Olichon, Thomas Landes, Laetitia Arnauné-Pelloquin, Laurent J. Emorine, Valérie Mils, et al.. Effects of OPA1 mutations on mitochondrial morphology and apoptosis: relevance to ADOA pathogenesis.: OPA1: mitochondrial morphology, apoptosis, and optic atrophy. Journal of Cellular Physiology, 2007, 211 (2), pp.423-30. 10.1002/jcp.20950 . inserm-00164120

\section{HAL Id: inserm-00164120 https://www.hal.inserm.fr/inserm-00164120}

Submitted on 4 Sep 2009

HAL is a multi-disciplinary open access archive for the deposit and dissemination of scientific research documents, whether they are published or not. The documents may come from teaching and research institutions in France or abroad, or from public or private research centers.
L'archive ouverte pluridisciplinaire HAL, est destinée au dépôt et à la diffusion de documents scientifiques de niveau recherche, publiés ou non, émanant des établissements d'enseignement et de recherche français ou étrangers, des laboratoires publics ou privés. 


\section{EFFECTS OF OPA1 MUTATIONS ON MITOCHONDRIAL MORPHOLOGY} AND APOPTOSIS: RELEVANCE TO ADOA PATHOGENESIS*

Aurélien Olichon $^{\S}$, Valérie Mils ${ }^{\S}$, Laetitia Arnauné-Pelloquin ${ }^{\S}$, Laurent J. Emorine $^{\S}$, Agnès Guichet ${ }^{\Uparrow}$, Cécile Delettre ${ }^{\ddagger}$, Christian Hamel ${ }^{\ddagger}$, Patrizia AmatiBonneau", Pascal Reynier ${ }^{\#}$, Dominique Bonneau", Guy Lenaers ${ }^{\S \sharp}$ and Pascale Belenguer ${ }^{\S}$.

Fom the ${ }^{\S}$ Laboratoire de Biologie Cellulaire et Moléculaire du Contrôle de la Prolifération, Université Paul Sabatier, Toulouse, France. "Service de Génétique Médicale, Centre Hospitalier Universitaire, Angers, France.

"INSERM U583, Institut des Neurosciences de Montpellier, Montpellier, France.

"INSERM U694, and Laboratoire de Biochimie et Biologie Moléculaire, Centre Hospitalier Universitaire, Angers, France.

Running title: OPA1: mitochondrial morphology, apoptosis, and optic atrophy

Address correspondence to : Pascale Belenguer, Laboratoire de Biologie Cellulaire et Moléculaire du Contrôle de la Prolifération, Université Paul Sabatier, 118 route de Narbonne, 31062 Toulouse cedex 04, France. Tel. (33/0) 5615562 38; Fax. (33/0) 561 5581 09; E-Mail : pascale.belenguer@cict.fr

To characterize the molecular links between type-1 autosomal dominant optic atrophy and OPA1 dysfunctions, the effects of pathogenic alleles of this dynamin on mitochondrial morphology and apoptosis were analyzed either in fibroblasts from affected individuals, or in HeLa cells transfected with similar mutants. The alleles were missense substitutions in the GTPase domain $\left(O P A 1^{\mathrm{G} 300 \mathrm{E}}\right.$ and OPA1 $\left.{ }^{\mathrm{R} 290 \mathrm{Q}}\right)$ or deletion of the GTPase effector domain $\left(\right.$ OPA1 $\left.^{\Delta 58}\right)$. Fragmentation of mitochondria and apoptosis increased in OPA1 ${ }^{\mathrm{R} 290 \mathrm{Q}}$ fibroblasts and in OPA1 ${ }^{\mathrm{G} 300 \mathrm{E}}$ transfected HeLa cells. OPA1 ${ }^{\triangle 58}$ did not influence mitochondrial morphology but increased the sensitivity to staurosporine of fibroblasts. In these cells, the amount of OPA1 protein was half that in control fibroblasts. We conclude that GTPase mutants exert a dominant negative effect by competing with wild-type alleles to integrate into fusion-competent complexes whereas C-terminal truncated alleles act by haploinsufficiency. We present a model where antagonistic fusion and fission forces maintain the mitochondrial network within morphological limits that are compatible with cellular functions. In the retinal ganglion cells of patients suffering type-1 autosomal dominant optic atrophy, OPA1-driven fusion cannot adequately oppose fission thereby rendering them more sensitive to apoptotic stimuli and eventually leading to optic nerve degeneration.

Autosomal dominant optic atrophy $\left(\mathrm{ADOA}^{1}\right.$; MIM\#165500) is the most common form of inherited optic neuropathy with a frequency of 1:12 000 to 1:50 $000 \quad(1,2)$. This disease is characterized by the insidious onset of visual impairment in early childhood with moderate to severe loss of visual acuity, temporal optic disc pallor, abnormalities of color vision and caecocentral visual field 
scotoma (3-5). Electrophysiological and histopathological studies have suggested that the underlying defect is retinal ganglion cell (RGC) degeneration leading to atrophy of the optic nerve $(3,6)$, as observed in Leber hereditary optic atrophy (LHON) a maternally transmitted disease caused by mtDNA mutations (7).

Among the four loci for ADOA (8-11) the most common is OPA1 which was found by us and others to be attributable to mutations in the OPAl gene located on chromosome 3q28-29 (12,13). This gene spans approximately $100 \mathrm{kbp}$ and is composed of 30 coding exons of which exons $4,4 \mathrm{~b}$ and $5 \mathrm{~b}$ are alternatively spliced generating $8 \mathrm{mRNA}$ isoforms (14). OPA1 transcripts are ubiquitously expressed in humans tisuues with particular isoforms predominating in the brain, retina, heart and muscle (12-14). In agreement we these observations several isoforms of the OPA1 protein were detected in different mammalian tissues, again showing a somewhat specific distribution (15). The OPA1 gene encodes a mitochondrial protein related to the dynamins $(12,15)$. It displays a GTPase domain with the three GTP binding motifs and a dynamin signature, and a coiled-coil C-terminal domain that could correspond to the dynamin GTPase effector domain (GED) involved in oligomerisation and catalytic activation $(16,17)$. In the $\mathrm{N}$-terminal region of OPA1 a canonical mitochondrial sequence targets the protein to the mitochondria $(15,18,19)$. OPA1 is localised to the inter-membrane space, and has been shown to be associated with the inner or outer membranes depending on the study $(15,19,20)$. Yeast orthologs of OPA1, Msp1p in S. pombe and Mgm1p in $S$. cerevisiae, shift the equilibrium between the fusion and fission forces (21-23) that act on mitochondrial membranes to maintain the mitochondrial network morphology $(24,25)$ towards fusion. We have suggested that the function of this dynamin has been conserved during evolution since expression of OPA1 can complement the loss of the $m s p 1^{+}$gene in $S$. pombe (26). This was recently emphasized in mammalian cells where modulation of OPA1 expression indeed affected mitochondrial morphology $(20,27,28)$. Interestingly, loss of the conserved mitochondrial dynamin led to cell death both in yeast and in human cells, by an apoptotic process in the latter species $(23,27,29,30)$.

Type-1 ADOA shows variable expression, both between and within families, ranging from an asymptomatic state to complete blindness (5), with no clear correlation with the many mutations found in the OPAl gene. More than 80 different mutations spread throughout the OPA1 coding sequence have been described so far (31). One of these, corresponding to the deletion of the entire OPA1 gene, provided evidence that haploinsufficiency is the cause of the disease (32). Accordingly, almost $50 \%$ of the mutations cause premature truncations of OPA 1 and nearly $40 \%$ are located in the GTPase domain, possibly leading to the loss of function of the dynamin. Nevertheless, we and others have demonstrated that expression of GTPase mutants of Mgm1p and Msp1p in yeasts containing a wild type allele of the dynamin exerts a dominant negative effect leading to cell death in $S$. pombe $(21,23,33)$. To clarify this point and to gain insight into the pathogenesis of type-1 ADOA we examined the effects of pathogenic mutations of OPA1 on mitochondrial morphology and apoptosis 
in transfected $\mathrm{HeLa}$ cells and in skin fibroblasts from ADOA patients.

\section{EXPERIMENTAL PROCEDURES}

Antibodies - OPA1 antibodies have been described previoulsly (15). Commercial antibodies were from the following sources: monoclonal anticytochrome c (Promega), monoclonal antiHSP60 (Sigma), Alexa-594 anti-rabbit IgG and Alexa-488 anti-mouse IgG (Molecular Probes) and anti-rabbit or anti-mouse IgGHRP (New England Biolabs).

Plasmid constructions - OPA1 mutations c. $889 \mathrm{G}>\mathrm{A}$ and c.2708delTTAG (12) yielding OPA $1^{\mathrm{G} 300 \mathrm{E}}$ and OPA1 $1^{\Delta 58}$ respectively, were engineered by PCR using the following antisense oligonucleotides : (G300E:5'-CACTAGTCTT TTCTGCAGACTGATCTCCA-3' and $\triangle 58: 5^{\prime}$ GGGATCCTAATCGCCTTCAGTATTTG-3').

PCR fragments were cloned in the TopopCRII vector (Promega), sequenced, and reintroduced into the pCCEY-OPA1 plasmid.

Cell culture and transfection - HeLa cells were cultured in DMEM, 10\% FCS, 5 $\% \mathrm{CO}_{2}$. Transfections were performed with the Lipofectamine 2000 reagent (Invitrogen) (27). Fibroblasts, obtained from patients by skin biopsy after obtaining their informed consent, were cultured in RPMI 1640, 10\% FCS, $5 \%$ $\mathrm{CO}_{2}$. Inhibition of caspases was achieved with $100 \mu \mathrm{M} \quad \mathrm{z}$-VAD-fmk (VWR). Staurosporine (Sigma) was used at a concentration of $75 \mathrm{nM}$ for 24 hours.

Western blots - Transfected HeLa cells or skin fibroblasts were harvested, washed once in ice-cold PBS, and then solubilised in Laemelli sample buffer for $10 \mathrm{~min}$ at $90^{\circ} \mathrm{C}$ or in $50 \mathrm{mM}$ Tris $\mathrm{HCl} \mathrm{pH} \mathrm{7.5,250}$ $\mathrm{mM} \mathrm{NaCl}, 5 \mathrm{mM}$ EDTA, 5 mM EGTA, 1
mM DTT, $0.1 \%$ TritonX100, 0.1\% SDS, $1 \%$ DOC, $1 \%$ NP40 containing a cocktail of protease inhibitors (Roche) for $30 \mathrm{~min}$ at $4{ }^{\circ} \mathrm{C}$ respectively. Equal amount of cells $\left(5.10^{5}\right)$ or proteins $(50 \square \mathrm{g})$ were run on $7 \%$ SDS-polyacrylamide gels and transferred to nitrocellulose. Immuno-detection (antiOPA1: $1 / 300$ or $1 / 200$; anti-actin: $1 / 10000$; anti-HSP60: $\quad 1 / 200 ; \quad$ anti-IgG-HRP: $1 / 10000)$ was performed with kit from NEN.

Microscopy - Cells grown on glass coverslips were fixed in $3.7 \%$ paraformaldehyde in PBS $\left(30 \mathrm{~min}, 4^{\circ} \mathrm{C}\right)$, permeabilized in $100 \%$ methanol (1 min, $20^{\circ} \mathrm{C}$ ), then in PBS $+0.2 \%$ Triton X-100 (10 $\mathrm{min}$, room temperature) and immunolabelled in PBS $+2 \%$ BSA, using the following antibodies (OPA1: $1 / 800$ or $1 / 160$; cytochrome c: $1 / 100$; Alexa-594 anti-rabbit IgG and Alexa-488 anti-mouse IgG: $1 / 500$ ) and stained with DAPI $(0.1 \square \mathrm{g} / \mathrm{ml})$. To quantify the phenotypes, mitochondria were stained directly in the cultures using 100nM CMXros Mitotracker $\square$ Red (Molecular Probes) for 30 minutes, then fixed and DAPI stained. Fluorescence images were captured and processed using a Leica DMIRE-2 microscope. For transmission electron microscopy, cells were microinjected with the different plasmids $(10 \mathrm{ng} / \mu \mathrm{l})$ in the presence of $10 \mathrm{~nm}$ gold bead conjugated immunoglobulins (EMS) using a Zeiss Axiovert microinjector. After 24 hours, cells were fixed for 1 hour with $4 \%$ glutaraldehyde in sodium cacodylate buffer, post-fixed for $1 \mathrm{~h}$ with $1 \%$ osmium tetroxide, dehydrated and embedded in Epon (EMS). Thin sections adsorbed onto nickel grids were stained with $1 \%$ uranyl acetate and $0.3 \%$ lead citrate, and imaged in a JEOL-1200 EX electron microscope at $80 \mathrm{kV}$. 


\section{RESULTS}

Effects of over-expression of pathogenic OPA1 alleles on mitochondrial morphology and apoptosis in HeLa cells To characterize the molecular links between type-1 ADOA and OPA1 dysfunction we analyzed the effects of over-expression of pathogenic alleles of the dynamin on mitochondrial morphology and on apoptosis. The mutations corresponded to the G300E substitution in the G1 motif of the GTPase domain and to the truncation of the last 58 amino acids in the GED-like domain of the protein. These pathological alleles (OPA1 ${ }^{\mathrm{G} 300 \mathrm{E}}$ and OPA $1^{\Delta 58}$ respectively) and the wild-type allele $\left(\mathrm{OPA} 1^{\mathrm{wt}}\right)$ were transiently transfected in HeLa cells.

After transfection (24h), HeLa cells produced equivalent amounts of OPA $1^{\mathrm{wt}}$ and OPA $1^{\mathrm{G} 300 \mathrm{E}}$ which showed a similar migration pattern upon SDS-PAGE. Two major bands were detected superimposed on the endogenous OPA1 isoforms that were visualized in the mock transfected cells (Fig. 1A). In comparison, the expression levels of OPA $1^{\Delta 58}$ were lower but the electrophoretic pattern was similar with two bands of a higher mobility being detected, consistent with a 58 residue deletion (Fig. 1A).

Mitochondrial network morphology and OPA1 labelling were next assessed using mitotracker red and anti-OPA1 antibodies respectively. In untransfected cells (Fig. 1B, panel a), Mitotracker labelling revealed elongated tubules forming a filamentous network. In these cells endogenous OPA1, visualized using a low antibody dilution (1/160), mostly colocalized with the mitotracker (Fig. $1 B$ panels a-c). It however appeared as discrete dots distributed along mitochondrial tubules, particularly distinguishable at the cellular cortex where the mitochondrial density was much lower. Twenty four hours after transfection with a control YFP-expressing vector, cells displayed a filamentous mitochondrial network (Fig. $1 B$ panel m, Fig. $1 C$ ). Overexpression of $O P A 1^{\text {wt }}$ altered mitochondrial morphology in transfected cells, visualized using a high antibody dilution that does not reveal endogenous OPA1 (1/800), leading to the disappearance of the elongated tubules and augmentating the numbers of intermediate and punctuated mitochondria (Fig. $1 B$ panels d-f and Fig. 1C). Over-expression of $\mathrm{OPA} 1^{\mathrm{G} 300 \mathrm{E}}$ induced a more severe fragmentation of the network which in most cells was composed of round mitochondria, as visualized either by mitotracker or OPA1 antibodies (Fig. $1 B$ panels g-i and Fig. 1C). Conversely, cells transfected with OPA $1^{\Delta 58}$ showed a normal filamentous mitochondrial network (Fig. $1 B$, panel j, Fig. $1 C$ ). The over-expressed mutated dynamin appeared to be clustered in foci less evenly spread through the mitochondrial network than the endogenous OPA1 proteins, as seen in regions of the cells with less mitochondria (Fig. 1B, panels k-1).

The internal structure of the mitochondria was then analyzed by electron microscopy on HeLa cells comicroinjected with plasmid DNA and 10 $\mathrm{nm}$ gold beads cojugated to immunoglobulin to visualize injected cells. In agreement with the light microscopy observations, cells expressing YFP (Fig. 2, panels a-b) or OPA1 ${ }^{\Delta 58}$ (Fig. 2, panels h-i) showed mitochondria that appeared to be heterogeneous in length consistent with sections of a tubular shaped network, while cells expressing OPA1 ${ }^{\text {wt }}$ (Fig. 2, panels c- 
d) or $\mathrm{OPA} 1^{\mathrm{G} 300 \mathrm{E}}$ (Fig. 2, panels e-g) showed predominantly small spherical mitochondria. Furthermore, expression of $\mathrm{OPA} 1^{\mathrm{G} 300 \mathrm{E}}$ altered the inner membrane structure which showed disorganized cristae of irregular shape and volume reminiscent of apoptotic cells (Fig. 2, panels e-g). Such effects on the structure of the cristae were not observed in YFP, OPA $1^{\text {wt }}$ or OPA $1^{\Delta 58}$ expressing cells (Fig. 2 , panels a-d and h-i).

Finally, the numbers of apoptotic cells induced by over-expression of the various forms of OPA1 was quantifed $24 \mathrm{~h}$ after transfection by direct labelling of chromatin with DAPI. In contrast to OPA $1^{\text {wt }}$ and $O P A 1^{\Delta 58}$ which had no effect on the number of apoptotic-like nucleus when compared to control YFP expressing cells, $20 \%$ of the cells transfected by $\mathrm{OPA}^{\mathrm{G} 300 \mathrm{E}}$ showed a nucleus containing condensed and fragmented chromatin (Fig. $3 A$ ). Such cells did not appear in the presence of the caspase inhibitor Z-VADfmk (data not shown). We then investigated whether apoptosis induced by over-expression of OPA $1^{\mathrm{G} 300 \mathrm{E}}$ depended on cytochrome $\mathrm{c}$ release. Before processing for immuno-cytochemistry with anti-OPA1 $(1 / 800)$ or anti-cytochrome c antibodies, the transfected cells were incubated with Z-VAD-fmk to prevent cells from fully initiating the apoptotic process and detaching from the growth support. A significant proportion $(7 \%, \mathrm{n}=300)$ of cells over-expressing $\mathrm{OPA} 1^{\mathrm{G} 300 \mathrm{E}}$ showed an homogenous cytoplasmic fluorescence when examined for cytochrome c labeling (Fig. 3B, panels g-l). In contrast in cells over-expressing OPA $1^{\text {wt }}$ (Fig. $3 B$, panels ac) or $\mathrm{OPA}^{\Delta 58}$ (Fig. $3 B$, panels d-f) cytochrome $\mathrm{c}$ fluorescence segregated to the mitochondrial network.
Mitochondrial morphology and sensitivity to apoptotic death in cells from type-1 ADOA patients - To further clarify the molecular links between type-1 ADOA and OPA1 mutations we extended the above observations to cells from ADOA patients. We thus examined mitochondrial morphology and the sensitivity to apoptosis of skin fibroblasts from patients carrying either the substitution R290Q in the GTPase domain of OPA1 $\left(\mathrm{OPA} 1^{\mathrm{R} 290 \mathrm{Q}}\right.$, c. $869 \mathrm{G}>\mathrm{A}$ ) or the deletion of the last 58 residues of OPA1 (OPA $1^{\triangle 58}$, c.2708delTTAG).

The morphology of the mitochondrial network was assessed using mitotracker. In two ADOA unaffected individuals $70 \%$ of the cells showed a filamentous mitochondrial network. Few cells (2\%) displayed a punctuated network with round mitochondria and the remaining cells (28\%) had an intermediate phenotype with mitochondria of both types (Fig. 4A, B). On the contrary mitochondria from a patient bearing the $\mathrm{OPA} 1^{\mathrm{R} 290 \mathrm{Q}}$ allele were highly fragmented (Fig. 4A, B); most cells with a filamentous network disappeared, incresasing the numbers of cells with punctuated mitochondria, while the proportion of cells with mixed mitochondrial phenotypes was almost unaffected. The mitochondrial phenotype of fibroblasts from a patient bearing the $\mathrm{OPA}^{158}$ allele was qualitatively and quantitatively undistinguishable from that of controls cells (Fig. 4A, $B$ ).

The susceptibility to staurosporineinduced apoptosis was then assessed (Fig. $4 B$ ). After $24 \mathrm{~h}$ of exposure to $75 \mathrm{nM}$ staurosporine approximately $10 \%$ of cells from the two unaffected individuals showed an apoptotic-like nucleus with condensed and fragmented chromatin. In comparison, skin fibroblasts from patients 
carrying either $\mathrm{OPA} 1^{\mathrm{R} 290 \mathrm{Q}}$ or $\mathrm{OPA} 1^{\Delta 58}$ allele showed an increased sensitivity to staurosporine-induced apoptosis (27 and $22 \%$ respectively). When cultures were not treated with staurosporine, apoptotic cells were observed at a frequency of 1 to $3 \%$ in both the controls and type- 1 ADOA patients.

Finally, Western blots using antiOPA1 antibodies were performed on extracts from skin fibroblasts from both unaffected and type-1 ADOA patients (Fig. $4 C$ ). Three major OPA1 isoforms were detected in control skin fibroblasts. In cells bearing OPA1 ${ }^{\mathrm{R} 290 \mathrm{Q}}$ a modification of this pattern was observed with a diminution of the faster migrating isoform and the appearance apparition of two bands (arrow heads in Fig. 4C). No qualitative modification of the OPA1 banding pattern was detected in cells bearing the OPA $1^{\Delta 58}$ allele but a reduction of about $50 \%$ of the amount of the three isoforms present in the control cells was reproducibly noticed while isoforms of higher electrophoretic mobility corresponding to C-terminally deleted dynamin (see Fig. $1 A$ ) were never observed.

\section{DISCUSSION}

To gain insight into the pathological processes associated with type-1 ADOA we have analyzed the mitochondrial phenotypes associated with the expression of pathogenic alleles of OPA1 either in $\mathrm{HeLa}$ cells transfected with the corresponding variants or in skin fibroblasts from patients bearing similar mutations. These mutations were representative of most alleles occurring in type-1 ADOA patients. The first class corresponds to missense substitutions in the GTPase domain which are predicted to affect guanyl nucleotide fixation and GTP hydrolysis in various GTPases $(34,35)$ including OPA1 (20). The second mutation is the most frequent in the patient population and induces a frame-shift deletion of 58 residues in the $\mathrm{C}$-terminal coiled-coil region that could correspond to the dynamin GTPase effector domain. Based on the role of the GED in the dynamins (36), this deletion is expected to alter the oligomerization and thus to abolish the stimulated GTPase activity of OPA1. Both types of mutants are presumably affected in their function since in contrast to OPA $1^{\text {wt }}$ they were unable to complement the deletion of $\mathrm{mspl}^{+}$, its orthologue in fission yeast (26).

Effects of OPA1 pathogenic alleles on mitochondrial morphology - Overexpression of OPA ${ }^{\mathrm{wt}}$ in HeLa cells caused mitochondrial fragmentation in agreement with former reports $(18,20)$. Nevertheless OPA1 $(20,27,28)$ and its yeast counterparts Mgm1p (21,22) and Msp1p (23) are believed to promote fusion of mitochondrial membranes. This discrepancy might be explained by a nonspecific effect due to over-expression of a membrane protein in tubular mitochondrial network. However, over-expression of OPA1 promoted mitochondrial elongation in MEF cells which the mitochondria are naturally fragmented (28). These observations may point to the existence of surveillance mechanisms which, while allowing local membrane dynamics, maintain the mitochondrial network within a morphological state compatible with its function in a given cell type. Such mechanism would oppose the antagonistic responses to modifications of either the fusion or fission levels which may compromise mitochondrial function when 
unrestrained. The fragmentation observed here for OPA $1^{\mathrm{wt}}$ could be due either to the imbalance induced by constitutive overexpression or could represent a bias of the control mechanisms towards fission.

Upon overexpression of $\mathrm{OPA} 1^{\mathrm{G} 300 \mathrm{E}}$ in HeLa cells mitochondrial fission occurred to a significantly greater extent than for OPA $1^{\mathrm{wt}}$ although the two proteins were expressed at similar levels. Fragmentation of mitochondria induced by alteration of the catalytic domain has been well documented for Mgm1p and Msp1p in yeast $(21-23,33)$ and more recently for OPA1 in mammals $(18,20,28)$. Both OPA $1^{\text {wt }}$ and $\mathrm{OPA} 1^{\mathrm{G} 300 \mathrm{E}}$ have functional GED-like domains and may thus able to incorporate into fusion-competent complexes. For OPA $1^{\text {wt }}$ this would result in increased oligomerization-stimulated GTPase and fusion activities and thus inducing a counteracting increase in fission (Fig. 5). On the contrary, integration of OPA $1^{\mathrm{G} 300 \mathrm{E}}$ into these complexes may have largely decreased GTPase-stimulated activity and fusion competency, leaving the fission forces almost unopposed and yielding a highly fragmented network (Fig. $5)$. This type of dominant negative mechanism is well documented for the conventional dynamins with deficient GTPase activity $(35,37)$. The lack of effect of OPA $1^{\Delta 58}$ may relate to the weaker expression of OPA1 $1^{\triangle 58}$ as compared to OPA $1^{\text {wt }}$ or $\mathrm{OPA} 1^{\mathrm{G} 300 \mathrm{E}}$. However OPA1 carrying a deletion of its potential GED may be unable to incorporate into oligomers and thus be unable to influence mitochondrial network dynamics in this manner.

We then examined the effects of the OPA1 pathogenic mutations under pathophysiological expression conditions. Highly fragmented mitochondria were observed in skin fibroblasts isolated from patients carrying the R290Q substitution suggesting that, as in $\mathrm{HeLa}$ cells expressing $\mathrm{OPA} 1^{\mathrm{G} 300 \mathrm{E}}$, a dominant negative effect is responsible for the fragmentation of the mitochondrial network (Fig. 5). As transfected HeLa cells, OPA $1^{\Delta 58}$ expressing fibroblasts showed a normal filamentous mitochondrial network. In these cells the amount of OPA1 was half that in control fibroblasts and was certainly produced from the wild-type allele only since no faster migrating bands corresponding to the C-terminal deletion were seen. During development cells may have adapted to a such situation by parallel diminution of the steady state fission forces to maintain a filamentous morphology of mitochondria (Fig. 5). Indeed, in RNAi experiments, fragmentation of mitochondria almost strictly paralleled the reduction in OPA1 levels $(27,28)$.

\section{Effects of OPA1 pathogenic alleles on} cell viability; relationships with mitochondrial morphology - The viability of cells expressing the various OPA1 isoforms was investigated since manipulation of the expression and/or activity of mitochondrial proteins involved in mitochondrial morphology has often been associated with cell death $(27,30,38$ 42). In fibroblasts from type-1 ADOA patients the OPA1 ${ }^{\mathrm{R} 290 \mathrm{Q}}$ allele behaved similarly to $\mathrm{OPA} 1^{\mathrm{G} 300 \mathrm{E}}$ in HeLa cells by increasing their sensitivity to apoptosis. On the contrary, OPA $1^{\Delta 58}$ had no effects in HeLa cells but induced skin fibroblasts to die upon treatment with sub-optimal doses of staurosporine.

Altogether, these observations may be interpreted according to our model of the 
regulation of mitochondrial morphology (Fig. 5). In HeLa cells, high-level overexpression of $\mathrm{OPA} 1^{\mathrm{G} 300 \mathrm{E}}$ almost annihilated the oligomerization-induced stimulation of GTPase activity by a dominant negative mechanism. Collapse of fusion activities left fission forces almost unrestricted and thereby induced fragmentation of the mitochondrial network beyond the level compatible with its function, followed by cell death. In skin fibroblasts, OPA1 ${ }^{\mathrm{R} 290 \mathrm{Q}}$ acted by similar a dominant negative mechanism, but to a lesser extent since it was expressed at comparable levels as OPA $1^{\mathrm{wt}}$; fragmentation was less intense and remained compatible with viability. However, staurosporine-induced mitochondrial fission (38) could not be sufficiently balanced by antagonistic fusion forces to maintain the mitochondrial network within acceptable limits and this ultimately led to cell death. Because of its inability to oligomerize and thus to integrate into fusion complexes, OPA $1^{\Delta 58}$ had no effects on HeLa cells which express physiological levels of wild-type OPA1. In cells from type-1 ADOA patients, the level of OPA $1^{\text {wt }}$ was half those of normal cells. Such truncated alleles could thus act by haplo-insufficiency rather than in a dominant negative manner, by promoting a diminution of the maximal stimulated GTPase and fusion activities of OPA1containing complexes, thereby increasing vulnerability to mitochondrial fragmentation and eventually cell death.

Physiopathology of type-1 ADOA - Our results fit with the two possible hypotheses that have been proposed as the pathophysiological processes underlying dominantly inherited diseases. Thus, among the 80 OPA1 mutations, those occuring in the GTPase domain would exert a dominant negative effect, while the C-terminally truncated alleles would cause haplo-insufficiency, as proposed for the deletion of the entire coding sequence (32). It may be predicted that many of the missense mutations that do not affect the intrinsic GTPase activity of OPA1 or its ability to form oligomers, may act by altering the transduction mechanisms that normally promote its oligomerisationstimulated GTPase activity.

Since both the R290Q and $\Delta 58$ alleles of OPA1 increased the sensitivity of cells to apoptosis this may represent the pathophysiological process leading to the neurodegeneration of RGC, as suggested for mitochondrial DNA mutations associated with the LHON syndrome (4346). In the RGC, the limits within which the mitochondrial morphology remains compatible with their function may be narrower than in other cells, rendering RGC more sensitive to apoptosis when mitochondrial morphology is not accurately controlled (Fig. 5). This is a crucial point since the number of optic atrophies associated with mutation of mitochondrial proteins is rapidly growing $(47,48)$. Furthermore, the importance of accurately controlled mitochondrial dynamics in neuronal cells is becoming increasingly well documented. Indeed, mutations in mitofusin-2, a mitochondrial GTPase involved in fusion of the outer membrane, correlate with Charcot-MarieTooth-2A neuropathy (49), while DRP1, a mitochondrial dynamin involved in fission of the outer membrane, is essential for morphogenesis and plasticity of the spines and synapses (50). Lack of OPA1promoted fusion, or more general defects in mitochondrial dynamics, could act either 
directly by affecting the interactions of pro- and/or anti-apoptotic molecules with membranes or indirectly by modifying the other essential functions of mitochondria (energy production, ROS or cardiolipid metabolism, calcium homeostasis) themselves linked to apoptotic sensors. In this context recent results showing a deficit in mitochondrial ATP in skeletal muscle (51) or a reduction in the amount of mtDNA in lymphocytes (52) from type 1 ADOA patients are of importance. 


\section{REFERENCES}

1. Lyle, W. (1990) Waterloo, Ontario: University of Waterlot Press

2. Kjer, B., Eiberg, H., Kjer, P., and Rosenberg, T. (1996) Acta Ophthalmol Scand 74(1), 3-7

3. Johnston, P. B., Gaster, R. N., Smith, V. C., and Tripathi, R. C. (1979) Am J Ophthalmol 88(5), 868-875

4. Hoyt, C. S. (1980) Ophthalmology 87(3), 245-251

5. Votruba, M., Moore, A. T., and Bhattacharya, S. S. (1998) J Med Genet 35(10), 793-800

6. Kjer, P., Jensen, O. A., and Klinken, L. (1983) Acta Ophthalmol (Copenh) 61(2), 300-312

7. Carelli, V., Rugolo, M., Sgarbi, G., Ghelli, A., Zanna, C., Baracca, A., Lenaz, G., Napoli, E., Martinuzzi, A., and Solaini, G. (2004) Biochim Biophys Acta 1658(1-2), 172-179

8. Eiberg, H., Kjer, B., Kjer, P., and Rosenberg, T. (1994) Hum Mol Genet 3(6), 977-980

9. Kerrison, J. B., Arnould, V. J., Ferraz Sallum, J. M., Vagefi, M. R., Barmada, M. M., Li, Y., Zhu, D., and Maumenee, I. H. (1999) Arch Ophthalmol 117(6), 805-810

10. Reynier, P., Amati-Bonneau, P., Verny, C., Olichon, A., Simard, G., Guichet, A., Bonnemains, C., Malecaze, F., Malinge, M. C., Pelletier, J. B., Calvas, P., Dollfus, H., Belenguer, P., Malthiery, Y., Lenaers, G., and Bonneau, D. (2004) J Med Genet 41(9), E110

11. Barbet, F., Hakiki, S., Orssaud, C., Gerber, S., Perrault, I., Hanein, S., Ducroq, D., Dufier, J. L., Munnich, A., Kaplan, J., and Rozet, J. M. (2005) $J$ Med Genet 42(1), e1

12. Delettre, C., Lenaers, G., Griffoin, J. M., Gigarel, N., Lorenzo, C., Belenguer, P., Pelloquin, L., Grosgeorge, J., Turc-Carel, C., Perret, E., Astarie-Dequeker, C., Lasquellec, L., Arnaud, B., Ducommun, B., Kaplan, J., and Hamel, C. P. (2000) Nat Genet 26(2), 207-210

13. Alexander, C., Votruba, M., Pesch, U. E., Thiselton, D. L., Mayer, S., Moore, A., Rodriguez, M., Kellner, U., Leo-Kottler, B., Auburger, G., Bhattacharya, S. S., and Wissinger, B. (2000) Nat Genet 26(2), 211-215

14. Delettre, C., Griffoin, J. M., Kaplan, J., Dollfus, H., Lorenz, B., Faivre, L., Lenaers, G., Belenguer, P., and Hamel, C. P. (2001) Human Genetics 109, 584-591

15. Olichon, A., Emorine, L. J., Descoins, E., Pelloquin, L., Brichese, L., Gas, N., Guillou, E., Delettre, C., Valette, A., Hamel, C. P., Ducommun, B., 
Lenaers, G., and Belenguer, P. (2002) FEBS Lett 523(1-3), 171-176.

16. Hinshaw, J. E. (2000) Annu Rev Cell Dev Biol 16, 483-519

17. Praefcke, G. J., and McMahon, H. T. (2004) Nat Rev Mol Cell Biol 5(2), 133-147

18. Misaka, T., Miyashita, T., and Kubo, Y. (2002) J Biol Chem 277(18), 15834-15842

19. Satoh, M., Hamamoto, T., Seo, N., Kagawa, Y., and Endo, H. (2003) Biochem Biophys Res Commun 300(2), 482-493

20. Griparic, L., van der Wel, N. N., Orozco, I. J., Peters, P. J., and van der Bliek, A. M. (2004) J Biol Chem 279(18), 18792-18798

21. Wong, E. D., Wagner, J. A., Scott, S. V., Okreglak, V., Holewinske, T. J., Cassidy-Stone, A., and Nunnari, J. (2003) J Cell Biol 160(3), 303-311

22. Sesaki, H., Southard, S. M., Yaffe, M. P., and Jensen, R. E. (2003) Mol Biol Cell 14(6), 2342-2356

23. Guillou, E., Bousquet, C., Daloyau, M., Emorine, L. J., and Belenguer, P. (2005) FEBS Lett 579(5), 1109-1116

24. Scott, S. V., Cassidy-Stone, A., Meeusen, S. L., and Nunnari, J. (2003) Curr Opin Cell Biol 15(4), 482-488

25. Rube, D. A., and van der Bliek, A. M. (2004) Mol Cell Biochem 256257(1-2), 331-339

26. Lenaers, G., Pelloquin, L., Olichon, A., Emorine, L. J., Guillou, E., Delettre, C., Hamel, C. P., Ducommun, B., and Belenguer, P. (2002) Yeast 19(13), 1125-1126.

27. Olichon, A., Baricault, L., Gas, N., Guillou, E., Valette, A., Belenguer, P., and Lenaers, G. (2003) J Biol Chem 278(10), 7743-7746

28. Cipolat, S., de Brito, O. M., Dal Zilio, B., and Scorrano, L. (2004) Proc Natl Acad Sci U S A

29. Pelloquin, L., Belenguer, P., Menon, Y., and Ducommun, B. (1998) Biochem Biophys Res Commun 251(3), 720-726

30. Lee, Y. J., Jeong, S. Y., Karbowski, M., Smith, C. L., and Youle, R. J. (2004) Mol Biol Cell 15(11), 5001-5011

31. Ferre, M., Amati-Bonneau, P., Tourmen, Y., Malthiery, Y., and Reynier, P. (2005) Hum Mutat 25(5), 423-428

32. Marchbank, N. J., Craig, J. E., Leek, J. P., Toohey, M., Churchill, A. J., Markham, A. F., Mackey, D. A., Toomes, C., and Inglehearn, C. F. (2002) J Med Genet 39(8), e47

33. Shepard, K. A., and Yaffe, M. P. (1999) J Cell Biol 144(4), 711-720

34. Bourne, H. R., Sanders, D. A., and McCormick, F. (1991) Nature 349, 117-127

35. Marks, B., Stowell, M. H., Vallis, Y., Mills, I. G., Gibson, A., Hopkins, C. 
R., and McMahon, H. T. (2001) Nature 410(6825), 231-235.

36. Sever, S., Muhlberg, A. B., and Schmid, S. L. (1999) Nature 398(6727), 481-486

37. Damke, H., Binns, D. D., Ueda, H., Schmid, S. L., and Baba, T. (2001) Mol Biol Cell 12(9), 2578-2589

38. Frank, S., Gaume, B., Bergmann-Leitner, E. S., Leitner, W. W., Robert, E. G., Catez, F., Smith, C. L., and Youle, R. J. (2001) Dev Cell 1(4), 515525.

39. James, D. I., Parone, P. A., Mattenberger, Y., and Martinou, J. C. (2003) J Biol Chem 278(38), 36373-36379

40. Sugioka, R., Shimizu, S., and Tsujimoto, Y. (2004) J Biol Chem 279(50), 52726-52734

41. Karbowski, M., and Youle, R. J. (2003) Cell Death Differ 10(8), 870-880

42. Perfettini, J. L., Roumier, T., and Kroemer, G. (2005) Trends Cell Biol 15(4), 179-183

43. Danielson, S. R., Wong, A., Carelli, V., Martinuzzi, A., Schapira, A. H., and Cortopassi, G. A. (2002) J Biol Chem 277(8), 5810-5815

44. Ghelli, A., Zanna, C., Porcelli, A. M., Schapira, A. H., Martinuzzi, A., Carelli, V., and Rugolo, M. (2003) J Biol Chem 278(6), 4145-4150

45. Zanna, C., Ghelli, A., Porcelli, A. M., Carelli, V., Martinuzzi, A., and Rugolo, M. (2003) Ann N Y Acad Sci 1010, 213-217

46. Battisti, C., Formichi, P., Cardaioli, E., Bianchi, S., Mangiavacchi, P., Tripodi, S. A., Tosi, P., and Federico, A. (2004) J Neurol Neurosurg Psychiatry 75(12), 1731-1736

47. Carelli, V., Ross-Cisneros, F. N., and Sadun, A. A. (2004) Prog Retin Eye Res 23(1), 53-89

48. Votruba, M. (2004) Eye 18(11), 1126-1132

49. Zuchner, S., Mersiyanova, I. V., Muglia, M., Bissar-Tadmouri, N., Rochelle, J., Dadali, E. L., Zappia, M., Nelis, E., Patitucci, A., Senderek, J., Parman, Y., Evgrafov, O., Jonghe, P. D., Takahashi, Y., Tsuji, S., Pericak-Vance, M. A., Quattrone, A., Battaloglu, E., Polyakov, A. V., Timmerman, V., Schroder, J. M., Vance, J. M., and Battologlu, E. (2004) Nat Genet 36(5), 449-451

50. Li, Z., Okamoto, K., Hayashi, Y., and Sheng, M. (2004) Cell 119(6), 873887

51. Lodi, R., Tonon, C., Valentino, M. L., Iotti, S., Clementi, V., Malucelli, E., Barboni, P., Longanesi, L., Schimpf, S., Wissinger, B., Baruzzi, A., Barbiroli, B., and Carelli, V. (2004) Ann Neurol 56(5), 719-723

52. Kim, J. Y., Hwang, J. M., Ko, H. S., Seong, M. W., Park, B. J., and Park, S. S. (2005) Neurology 64(6), 966-972 


\section{FOOTNOTES}

${ }^{*}$ We are indebted to the IFR 109 and Nacer Benméragui for technical help in electron microscopy, to Martine Cazales for microinjections, to Bertrand Reuge for assistance with fibroblats experiments and to Sherilyn Goldstone for correction of the manuscript. This work was supported by grants from the Centre National de la Recherche Scientifique, Université Paul Sabatier, Fondation pour la Recherche Médicale, Association Française contre les Myopathies, Rétina France, Fondation Electricité de France, GIS-Institut des Maladies Rares. AO. was a recipient of a fellowship from Association pour la Recherche sur le Cancer.

${ }^{1}$ The abbreviations used are : ADOA, Autosomal Dominant Optic Atrophy; YFP, Yellow Fluorescent Protein; mtDNA, mitochondrial DNA; DAPI, 4' 6'-diamino-2phenylindole; ORF, Open Reading Frame; GED, GTPase Effector Domain; RGC, retinal ganglion cells.

\section{FIGURE LEGENDS}

Fig. 1. Effects of over-expression of pathogenic OPA1 alleles on mitochondrial morphology in HeLa cells. HeLa cells were transfected or not (-) with empty vector (mock) or vectors encoding either wild type OPA1 (OPA1 ${ }^{\text {wt }}$ ), GTPase mutated OPA1 (OPA1 ${ }^{\mathrm{G} 300 \mathrm{E}}$ )' C-terminal deleted OPA1 (OPA1 ${ }^{\Delta 58}$ ) or YFP and grown for $24 \mathrm{~h}$. $A$, Western blot on HeLa cell extracts using antibodies against OPA1 (1/300) and actin. The positions of the molecular weight markers $(\mathrm{kDa})$ are shown. Bands corresponding to the OPA $1^{\Delta 58}$ allele are indicated by stars. $B$, Analysis of DAPI and Mitotracker ${ }^{\square}$ Red (panels $\mathrm{a}, \mathrm{d}, \mathrm{g}, \mathrm{j}$ and $\mathrm{m}$ ) staining and OPA1 immuno-labeling (b, e, h, k and $\mathrm{n}$ ) by fluorescence microscopy. OPA1 antibodies were diluted to 1/160 (a-c) or to 1/800 (d-o). A ten fold higher magnification of merged labeling corresponding to the boxes are shown in panels c, f, i, 1 and o. Untransfected cells are indicated by stars. $C$, The mitochondrial phenotypes observed in $B$ were quantified by examination of 300 transfected cells using MitoTracker ${ }^{\square}$ Red staining.

Fig.2. Effects of over-expression of pathogenic OPA1 alleles on mitochondrial ultrastructure in HeLa cells. Electron microscopic micrographs of thin section of HeLa cells showing the structure of mitochondria $24 \mathrm{~h}$ after micro-injection with vectors encoding YFP (panels a and b), OPA $1^{\text {wt }}$ (panels $\mathrm{c}$ and $\mathrm{d}$ ), OPA1 ${ }^{\mathrm{G} 300 \mathrm{E}}$ (panels e-g) or OPA1 ${ }^{\triangle 58}$ (panels hand i). The scale bars indicate $100 \mathrm{~nm}$.

Fig. 3. Effects of over-expression of pathogenic OPA1 alleles on apoptosis in HeLa cells. HeLa cells were transfected with vectors encoding OPA $1^{\text {wt }}$, OPA $1^{\mathrm{G} 300 \mathrm{E}}, \mathrm{OPA} 1^{\triangle 58}$ or YFP and cultured for $24 \mathrm{~h}$. A, Apoptotic nuclei showing highly condensed and fragmented chromatin cells were quantified by examination of 300 cells by fluorescence microscopy after DAPI staining. $B$, Cells treated with Z-VAD-fmk 4 hour after transfection were stained with DAPI and immuno-labelled with anti-OPA1 (1/800) 
(panels a, d, g and j) or anti-cytochrome c (panels b, e, h and k) antibodies. Overlays of fluorescences is shown in panels c, $\mathrm{f}, \mathrm{i}$ and $\mathrm{l}$. Untransfected cells are shown by stars.

Fig. 4. Mitochondrial morphology and susceptibility to apoptosis in skin fibroblasts from type 1 ADOA patients. Skin fibroblasts were obtained from patients suffering from type-1 ADOA bearing a mutation in the GTPase domain $\left(\mathrm{OPA} 1^{\mathrm{R} 290 \mathrm{Q}}\right)$ or a C-terminal deletion of OPA1 $\left(\mathrm{OPA}^{\Delta 58}\right)$ and from two unaffected individuals (control 1 and 2). Cells were analysed for mitochondrial morphology $(A)$ and nuclear phenotype $(B)$ by fluorescence microscopy using MitoTracker ${ }^{\square}$ Red and DAPI staining respectively. Typical mitochondrial phenotypes and apoptotic nuclei showing condensed and fragmented chromatin after $75 \mathrm{nM}$ staurosporine treatment were quantified by examination of 200 cells. $C$, Western blots on proteins extracted from the same fibroblasts as in B, using antibodies against OPA1 (1/200), HSP60 and actin.

Fig. 5. Mitochondrial morphology and apoptosis, relevance to type-1 ADOA.

Mitochondrial morphology is regulated by highly dynamics, antagonistic fusion and fission forces (grey and white arrows, respectively). According to cellular needs, it may vary within certain limits from a reticular tubular network to small individual grains (top panels). Beyond a fission threshold $(Q)$, which may vary in relation to cell type (HeLa, fibroblasts or RGC), cells gradually become more susceptible to apoptotic stimuli and cell death (grey gradation).

In HeLa cells and primary fibroblasts fusion and fission forces equilibrate with a slight advantage for fusion, yielding a tubular mitochondrial network. In HeLa cells, constitutive over-expression of functional OPA1 (op OPA1 ${ }^{\text {wt }}$ ) increased mitochondrial fusion and triggered an overwhelming fission response. Over expression of the dominant negative allele $\mathrm{OPA} 1^{\mathrm{G} 300 \mathrm{E}}$ (op $\mathrm{OPA} 1^{\mathrm{G} 300 \mathrm{E}}$ ) almost totally annihilated mitochondrial fusion, leaving fission forces unopposed and inducing spontaneous apoptotic death.

In fibroblasts with one OPA1 ${ }^{\Delta 58}$ allele, fusion competency was decreased by haploinsufficiency but an adaptative, parallel diminution of fission forces maintained a reticular network. The $\mathrm{OPA} 1^{\mathrm{R} 290 \mathrm{Q}}$ allele further inhibited fusion by dominant negative mechanisms, yielding a punctuated mitochondrial network. In both cases, fusion forces were too reduced to efficiently oppose to fission induced by suboptimal doses of staurosporine. 


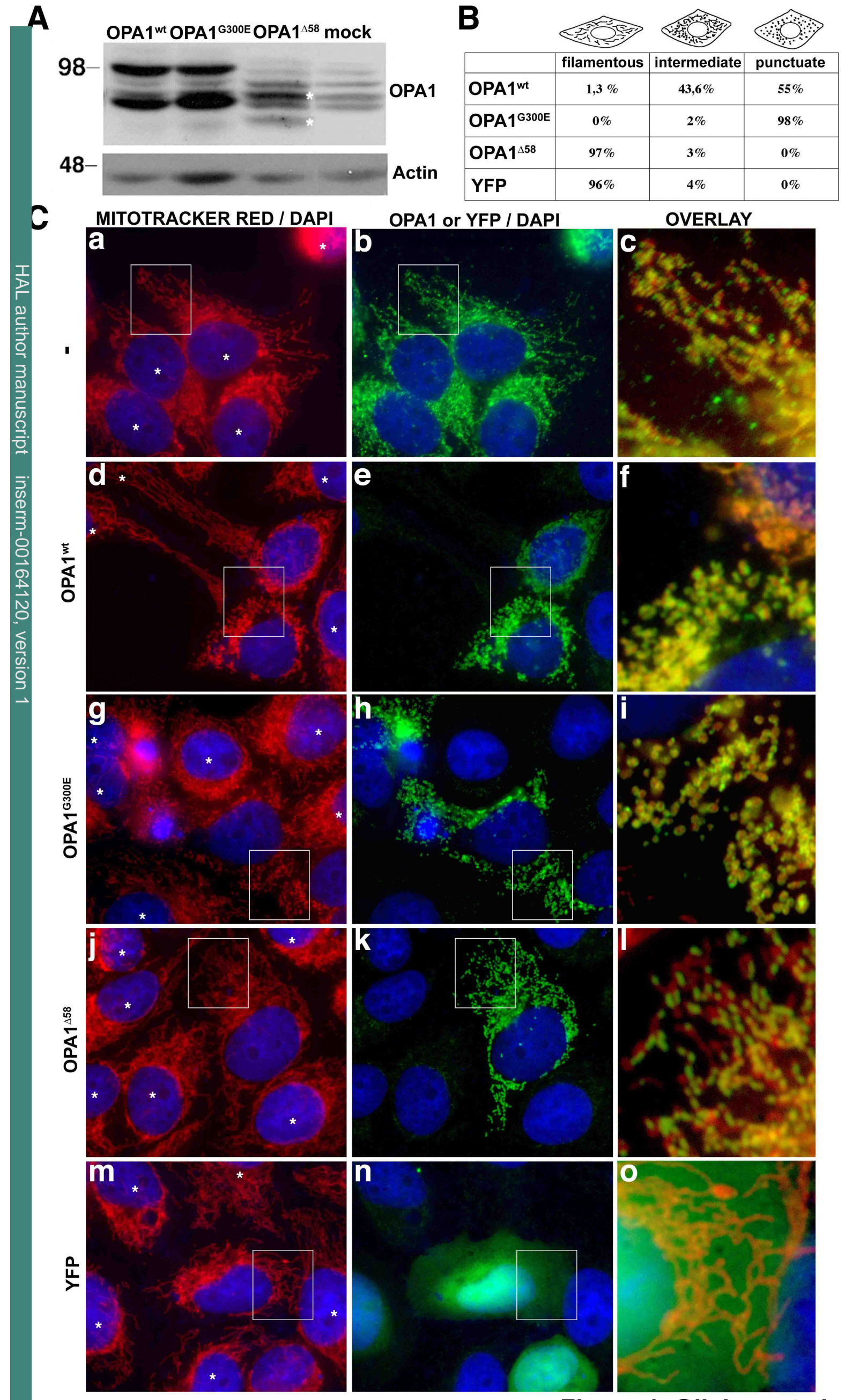

Figure 1, Olichon et al 
A

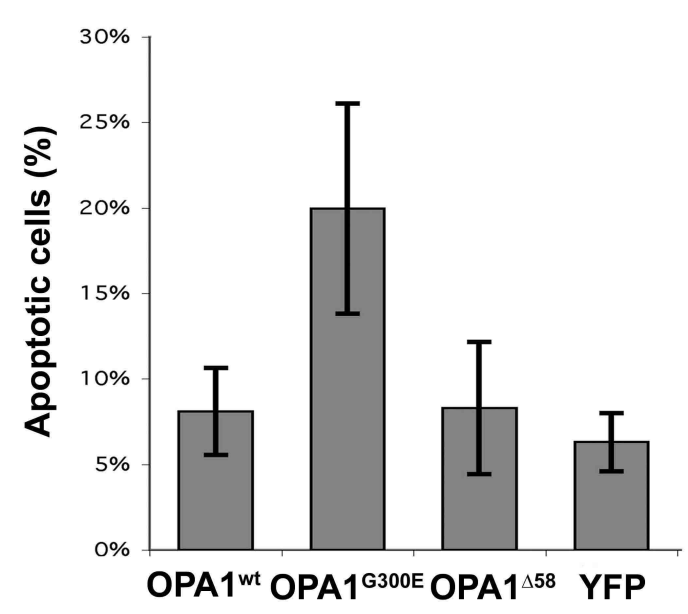

B

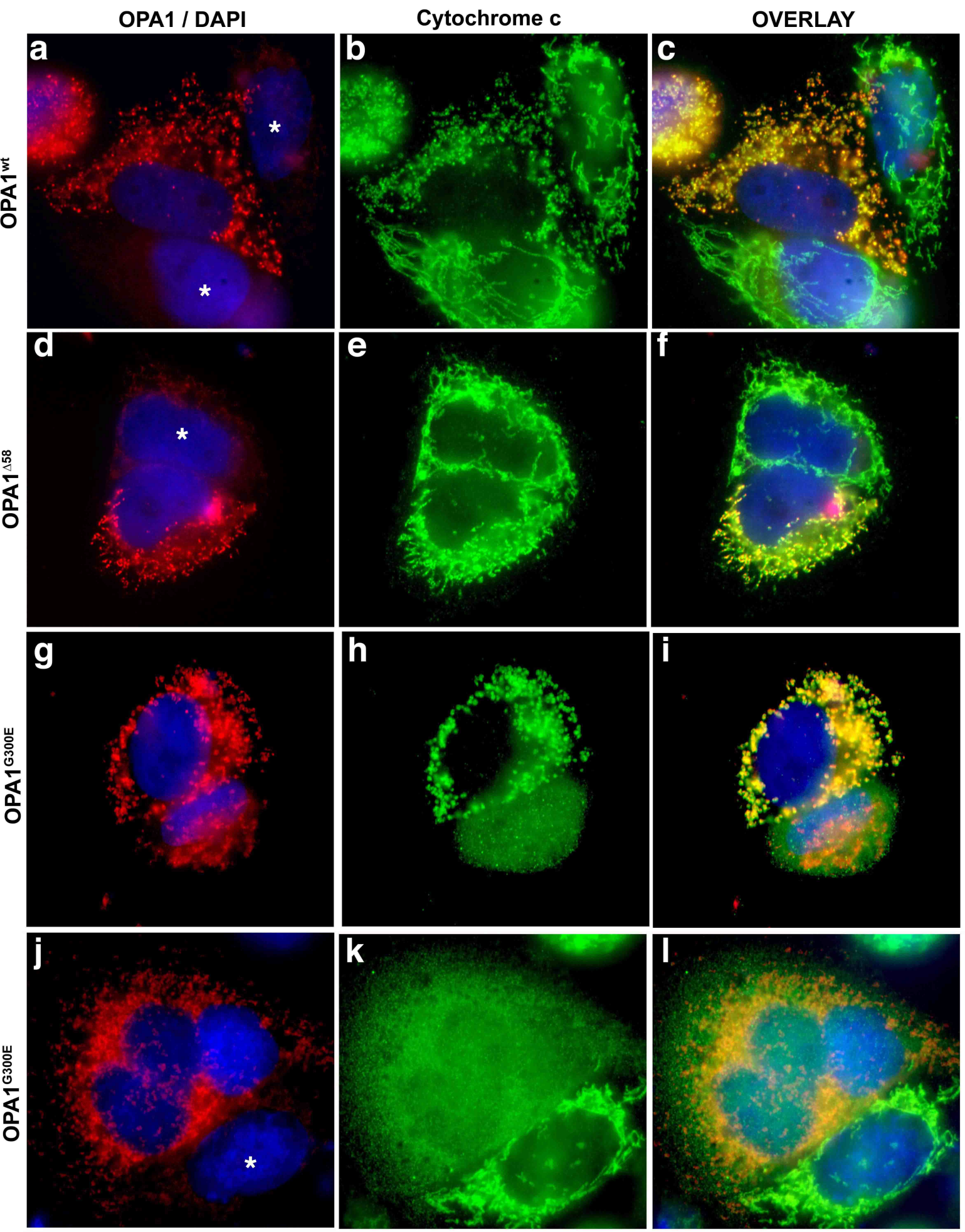

Figure 3, Olichon et al 
A

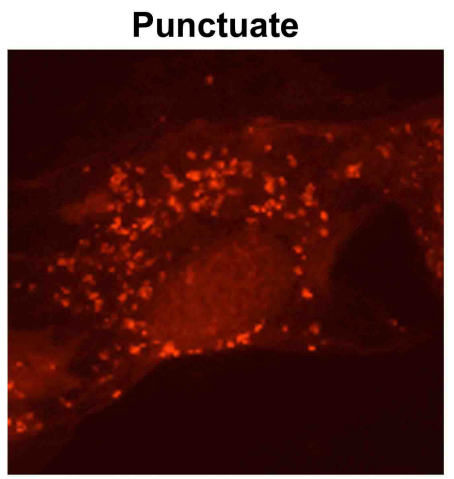

B

\begin{tabular}{|l|c|c|c|c|}
\hline & Filamentous & Intermediate & Punctuate & Apoptotic cells \\
\hline Control 1 & $71 \%$ & $26 \%$ & $3 \%$ & $12 \%$ \\
\hline Control 2 & $69 \%$ & $30 \%$ & $1 \%$ & $13 \%$ \\
\hline OPA1 $^{\text {R290Q }}$ & $3 \%$ & $37 \%$ & $60 \%$ & $27 \%$ \\
\hline OPA1 $^{458}$ & $70,5 \%$ & $25,5 \%$ & $4 \%$ & $22 \%$ \\
\hline
\end{tabular}

C

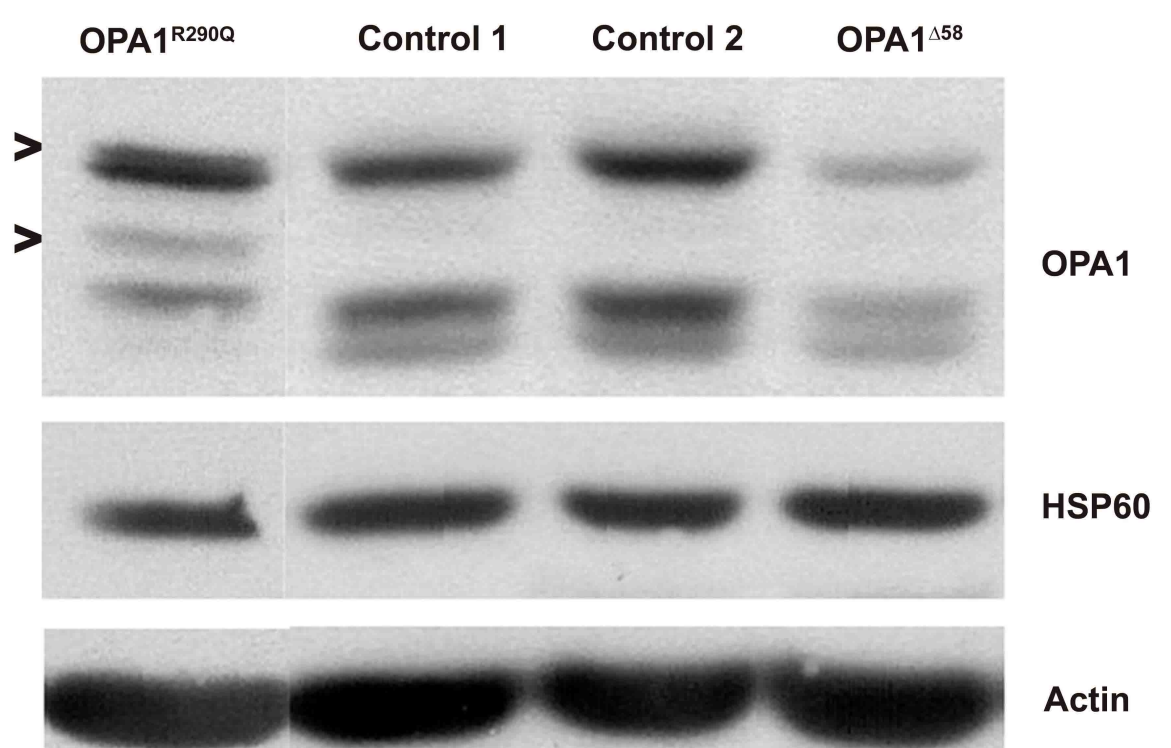

Figure 4, Olichon et al 


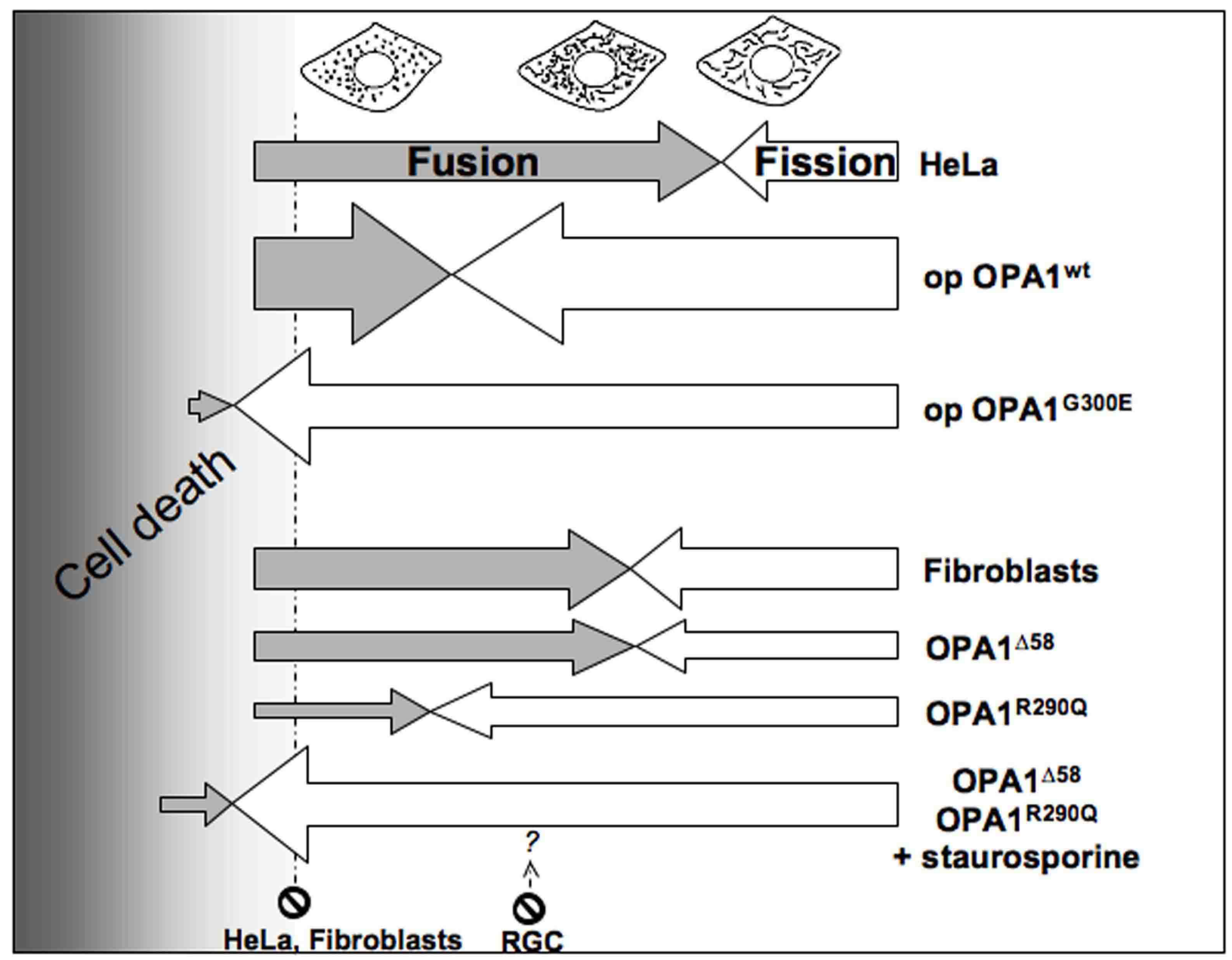

Figure 5, Olichon et al 